\title{
Synthesis and Properties of Segmented Poly(urethane-urea)s Containing Phosphorylcholine Moiety in the Side-Chain
}

\author{
By Yu NAGASE, ${ }^{1, *}$ Satoru NAKAJIMA, ${ }^{1}$ Masataka OKU, ${ }^{1}$ Yasuhiko IWASAKI, ${ }^{2}$ and Kazuhiko ISHIHARA ${ }^{3}$
}

In order to improve the biocompatibility of segmented polyurethane which has been widely used as a biomedical material, the synthesis of segmented poly(urethane-urea) containing phosphorylcholine (PC) moiety was carried out by using aromatic diamine monomer with PC unit. The obtained poly(urethane-urea)s were soluble in aprotic polar solvents such as NMP, DMSO and DMF, but insoluble in water, alcohol and acetone. In addition, it was confirmed from the results of blood contacting experiments that the polymer exhibited the excellent biocompatibility, even though the PC content was around $15 \mathrm{wt}$ \%, which would be due to the surface structure derived from PC side chain. From the results of stress-strain measurements, poly(urethane-urea) films exhibited the elastic properties, which were almost as same as those of segmented polyurethane. On the other hand, the gas permeability of the poly(urethane-urea) film, which consisted of the high permeable siloxane soft segment, slightly increased as compared with polyurethane film consisting the similar backbone component. KEY WORDS: Segmented Poly(urethane-urea) / Phosphorylcholine / Diamine Monomer / Polyaddition / Biocompatibility /

Mechanical Property /

Segmented polyurethanes (SPU) have been widely used in the practical medical devices ${ }^{1,2}$ as elastomers because of their suitable mechanical properties and biocompatibility, which consisted of short alternating blocks of soft and hard segments. The soft segment is typically a low glass transition temperature $\left(T_{\mathrm{g}}\right)$ polyether, polyester or polyalkylenediol, the molecular weights of which are 400-5000. The hard segment is usually a high glass transition temperature component, such as semicrystalline aromatic diisocyanate linked with a low molecular weight chain extender. The biocompatibility of SPU is thought to be derived from the micro phase separation of soft and hard segments. However, the blood compatibility of SPU is not enough to be applied for long-term implantation. It has been suggested that the biodegradation and cracking of the SPU occurred in vivo due to the adsorption of proteins, the adhesion of macrophages and the peroxide formation, ${ }^{3-5}$ which resulted in the reduction of the mechanical strength of SPU. Moreover, it was reported that the soft segment of SPU was degraded by the oxygen radicals produced from adherent macrophages. ${ }^{6}$ Therefore, several studies of the surface or chemical modification of SPU have been conducted to improve the blood compatibility through reducing the adhesion of cells and proteins. $^{7-11}$

On the other hand, 2-methacryloyloxyethyl phosphorylcholine (MPC) polymer has been developed as an excellent blood compatible material, which efficiently reduces the adhesion of cells and proteins on the polymer surface. ${ }^{12,13}$ The MPC polymer was designed based on the inspiration from the chemical structure of phospholipids polar group in biomembrane. Considerable attention has been given to biomedical polymers containing phospholipids functionality, and particularly to those with the phosphatidylcholine moiety, ${ }^{14,15}$ which is a major component of the extracellular surface of the phospholipids bilayer. Ishihara and his coworkers have demonstrated a great decrease in protein adsorption and platelet adhesion on MPC polymer containing phosphorylcholine groups, therefore, in these years, MPC polymer has been now widely applied in the biological and medical fields. ${ }^{16-22}$ They have also investigated the polymer composite consisting of SPU and MPC polymer, in order to reduce the protein adsorption on the polymer surface and to improve the biocompatibility of SPU. ${ }^{23-26}$

In this study, as another approach to improve the biocompatibility of SPU which has been widely used as a biomedical material, the synthesis of segmented poly(urethane-urea) chemically bonded to phosphorylcholine (PC) moiety was carried out by using aromatic diamine compound containing PC unit as a comonomer. We have been developing the synthesis of a novel aromatic diamine monomer with PC group, 2-(3,5-diaminophenylcarbonyloxy)ethyl phosphorylcholine, to prepare novel aromatic polyamides containing PC group in the side chain, the backbone component of which was durable as compared with that of MPC polymers. ${ }^{27}$ Then, it was revealed that PC group was also effective to improve the biocompatibility to such rigid polymer compounds, which would be due to the surface property covered with polar PC units. Therefore, in this paper, we attempted to prepare segmented poly(urethane-urea) containing PC group by using the diamine monomer with PC unit as a coupling reagent in the polyaddition of diols with diisocyanate, which would lead to new

\footnotetext{
'Department of Applied Chemistry, Graduate School of Engineering, Tokai University, 1117 Kitakaname, Hiratsuka 259-1292, Japan

${ }^{2}$ Department of Chemistry and Materials Engineering, Faculty of Chemistry, Materials and Bioengineering, Kansai University, 3-3-35 Yamate-cho, Suita 564-8680, Japan

${ }^{3}$ Department of Materials Engineering, School of Engineering, The University of Tokyo, 7-3-1 Hongo, Bunkyo-ku, Tokyo 113-8656, Japan

*To whom correspondence should be addressed (Tel: +81-463-58-1211, Fax: +81-463-50-2012, E-mail: yunagase@ keyaki.cc.u-tokai.ac.jp).
} 


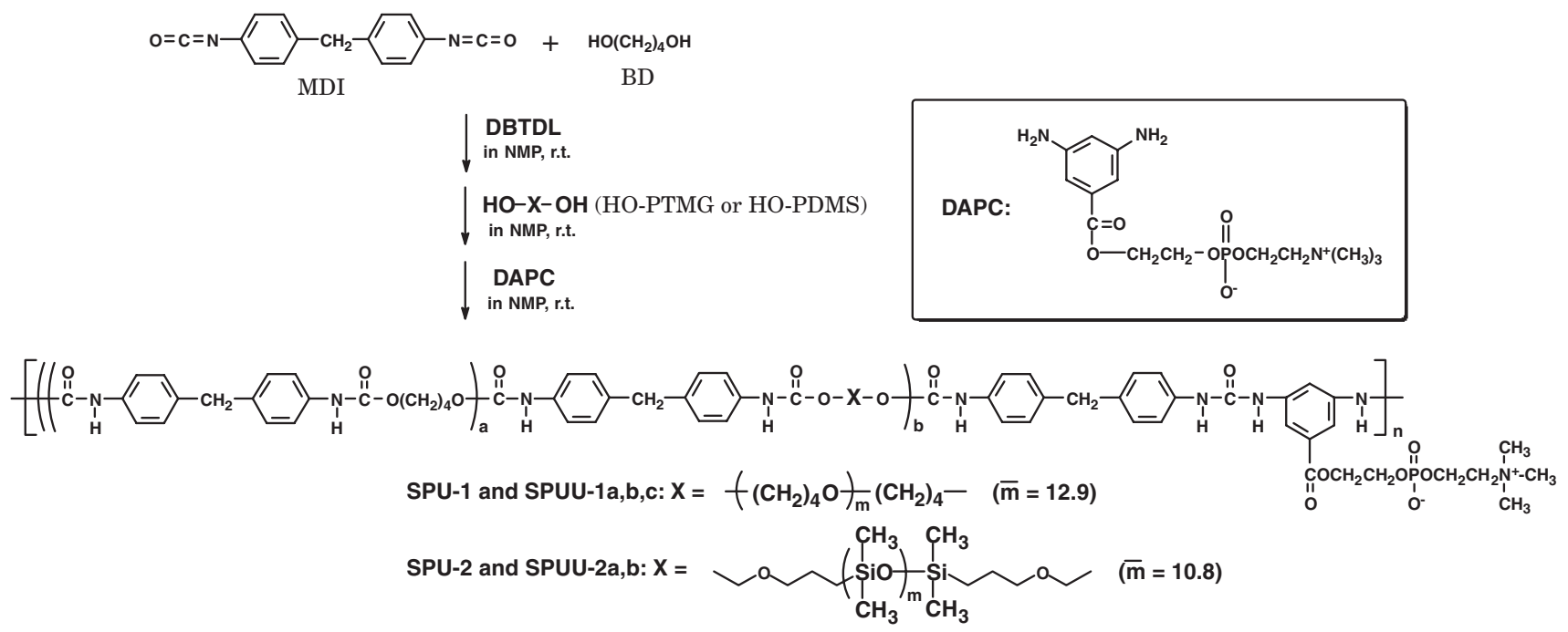

Scheme 1. Preparations of segmented poly(urethane-urea) containing PC unit.

biocompatible polymers derived from the characteristics of SPU and PC group. As soft segments, poly(tetramethylene glycol) (PTMG) and polydimethylsiloxane (PDMS) were introduced to compare the effect of PC group on the properties of polymers consisted of the different main chain structure. Then, the physical properties such as solubility, surface property, biological function as blood compatibility, mechanical property and gas permeability of the obtained polymers were investigated in detail to reveal the possibility as a practical biomaterial.

\section{EXPERIMENTAL}

\section{Materials}

The diamine monomer with PC unit, 2-(3,5-diaminophenylcarbonyloxy)ethyl phosphorylcholine (DAPC), was synthesized according to the procedure described in our previous paper. $^{27}$ MPC polymer, poly(MPC-co-butyl methacrylate) (PMB, MPC content: $30 \mathrm{~mol} \%$ ), was prepared according to the literature $^{12}$ as a reference sample for the blood compatibility. Hydroxyl-terminated poly(tetramethylene glycol) (HOPTMG, $\left.M_{\mathrm{n}}=1,000\right)$ was purchased from Tokyo Kasei Chemical Co. Ltd. and heated at over $80^{\circ} \mathrm{C}$ to remove moisture before use. Hydroxyethoxypropyl-terminated polydimethylsiloxane (HO-PDMS, $\left.M_{\mathrm{n}}=1,000\right)$ was purchased from Chisso Corporation and used as received. 4,4'-Diphenylmethane diisocyanate (MDI), 1,4-butanediol (BD) and dibutyltin dilaurate (DBTDL) were purchased from Tokyo Kasei Chemical Co. Ltd. and used as received. Other chemicals were used without further purification.

\section{Preparations of Segmented Poly(urethane-urea) with PC Unit (SPUU-1a,b,c)}

Under an argon atmosphere, BD $(0.36 \mathrm{~g}, 4.00 \mathrm{mmol})$ and DBTDL $(0.20 \mathrm{~g}, 0.32 \mathrm{mmol})$ were dissolved in a flask with $5.3 \mathrm{~mL}$ of $\mathrm{N}$-methyl-2-pyrrolidinone (NMP), and a solution containing MDI $(2.00 \mathrm{~g}, 7.99 \mathrm{mmol})$ in $5.0 \mathrm{~mL}$ of NMP was gradually added to the mixture at room temperature. After the mixture was stirred at $50^{\circ} \mathrm{C}$ for $2 \mathrm{~h}$, a solution of HO-PTMG $(2.66 \mathrm{~g}, 2.66 \mathrm{mmol})$ dissolved in $2.7 \mathrm{~mL}$ of NMP was added dropwise at $0{ }^{\circ} \mathrm{C}$. Then, after the mixture was stirred at $50{ }^{\circ} \mathrm{C}$ for $1 \mathrm{~h}$, a solution of DAPC $(0.48 \mathrm{~g}, 1.33 \mathrm{mmol})$ dissolved in $1.5 \mathrm{~mL}$ of NMP was added dropwise at $0^{\circ} \mathrm{C}$, and the mixture was stirred at room temperature for overnight. The reaction mixture was poured into excess methanol/diethyl ether (1/1 vol.) mixed solvents to provide a white precipitate, which was collected by filtration and purified by reprecipitation from its NMP solution to excess methanol/diethyl ether (1/1 vol.) mixed solvents. Finally, the product was dried in vacuo to give SPUU-1a as a white powder. Yield: $5.02 \mathrm{~g}(91.3 \%)$.

${ }^{1} \mathrm{H}$ NMR, $\delta\left(400 \mathrm{MHz}, \mathrm{DMSO}-d_{6}, \mathrm{ppm}\right): 1.53$ (m, - $\left.\mathrm{CH}_{2}-\right), 1.74$ (m, $\left.-\mathrm{CH}_{2}-\right), 3.15\left(\mathrm{~s},-\mathrm{N}\left(\mathrm{CH}_{3}\right)_{3}\right), 3.28$ (bs, $\left.-\mathrm{POCH}_{2} \mathrm{CH}_{2} \mathrm{~N}-\right), 3.78$ (s, - $\mathrm{PhC} \underline{H}_{2} \mathrm{Ph}-$ ), 4.12 (bs, $-\mathrm{POCH}_{2} \mathrm{CH}_{2} \mathrm{~N}-$ ), 4.34 (m, - $\mathrm{CH}_{2}-$ ), 4.42 (bs, - $\left.\mathrm{CH}_{2}-\right), 6.63$ (s, - $\left.\mathrm{Ph}-\right), 7.09$ (m, - $\left.\mathrm{Ph}-\right), 7.35$ (d, $J=7.80 \mathrm{~Hz},-\mathrm{Ph}-), 8.49$ (s, -NH-), 9.48 (s, -NH-).

SPUU-1b and SPUU-1c were prepared by the similar procedures of the preparation of SPUU-1a with changing the molar ratio of BD, HO-PTMG and DAPC as shown in Table I.

Preparations of Segmented Poly(urethane-urea) with PC Unit (SPUU-2a,b)

In the above polymerization reaction, HO-PDMS $(2.66 \mathrm{~g}$, $2.66 \mathrm{mmol}$ ) was used instead of HO-PTMG, and the similar reactions and reprecipitation were carried out to afford SPUU2a as a white powder. Yield: $5.10 \mathrm{~g}$ (92.7\%).

${ }^{1} \mathrm{H}$ NMR, $\delta$ (400 MHz, DMSO- $\left.d_{6}, \mathrm{ppm}\right): 0.01$ (s, $\left.-\mathrm{Si}\left(\mathrm{CH}_{3}\right)_{2}\right)$, $0.53\left(\mathrm{~m},-\mathrm{SiCH}_{2}-\right), 1.52\left(\mathrm{~m},-\mathrm{CH}_{2}-\right), 1.72\left(\mathrm{~m},-\mathrm{CH}_{2}-\right), 3.10(\mathrm{~s}$, $\left.-\mathrm{N}\left(\mathrm{CH}_{3}\right)_{3}\right), 3.33$ (m, - $\left.\mathrm{CH}_{2}-\right), 3.38$ (bs, $\left.-\mathrm{POCH}_{2} \mathrm{CH}_{2} \mathrm{~N}-\right), 3.80$ (s, $\left.-\mathrm{PhCH} \underline{\mathrm{H}}_{2} \mathrm{Ph}-\right), 4.13$ (bs, $\left.-\mathrm{POCH}_{2} \mathrm{CH}_{2} \mathrm{~N}-\right), 4.30$ (m, $\left.-\mathrm{CH}_{2}-\right), 4.42$ (m, - $\mathrm{CH}_{2}$ ), 6.63 (s, -Ph-), 7.10 (m, - Ph-), 7.35 (d, J=7.80 Hz, -Ph-), 8.50 (s, -NH-), 9.48 (s, -NH-). 
IR, v $\left(\mathrm{KBr}, \mathrm{cm}^{-1}\right): 3315(\mathrm{~N}-\mathrm{H}), 2961,2860(\mathrm{C}-\mathrm{H}), 1708$ $(\mathrm{C}=\mathrm{O}), 1590,1541,1508,1261(\mathrm{Si}-\mathrm{C}), 1240(\mathrm{P}=\mathrm{O}), 1025$ (SiO-Si), 798, 740.

SPUU-2b was prepared by the similar procedure of the preparation of SPUU-2a with changing the molar ratio of BD, HO-PDMS and DAPC as shown in Table I.

\section{Preparations of Segmented Polyurethane (SPU-1)}

Under an argon atmosphere, BD (0.48 g, $5.33 \mathrm{mmol})$ and DBTDL $(0.20 \mathrm{~g}, 0.32 \mathrm{mmol})$ were dissolved in a flask with $5.0 \mathrm{~mL}$ of NMP, and a solution containing MDI $(2.00 \mathrm{~g}$, $7.99 \mathrm{mmol}$ ) in $5.0 \mathrm{~mL}$ of NMP was gradually added to the mixture at room temperature. After the mixture was stirred at $50{ }^{\circ} \mathrm{C}$ for $2 \mathrm{~h}$, a solution of HO-PTMG $(2.66 \mathrm{~g}, 2.66 \mathrm{mmol})$ dissolved in $3.0 \mathrm{~mL}$ of NMP was added dropwise at $0{ }^{\circ} \mathrm{C}$. Then, after the mixture was stirred at $50{ }^{\circ} \mathrm{C}$ for $1 \mathrm{~h}$, the reaction mixture was poured into excess methanol/diethyl ether $(1 / 1$ vol.) mixed solvents to provide a white precipitate, which was collected by filtration and purified by reprecipitation from its NMP solution to excess methanol/diethyl ether (1/1 vol.) mixed solvents. Finally, the product was dried in vacuo to give SPU-1 as a white powder. Yield: $4.95 \mathrm{~g}$ (96.3\%).

${ }^{1} \mathrm{H}$ NMR, $\delta\left(400 \mathrm{MHz}, \mathrm{DMSO}-d_{6}, \mathrm{ppm}\right): 1.53\left(\mathrm{~m},-\mathrm{CH}_{2}-\right), 1.73$ (m, - $\left.\mathrm{CH}_{2}-\right), 3.28\left(\mathrm{~m},-\mathrm{CH}_{2}-\right), 3.78$ (s, $\left.-\mathrm{PhC}_{2} \mathrm{Ph}-\right), 4.30(\mathrm{~m}$, $\left.-\mathrm{CH}_{2}-\right), 7.04$ (d, $\left.J=8.30 \mathrm{~Hz},-\mathrm{Ph}-\right), 7.35$ (d, $\left.J=7.80 \mathrm{~Hz},-\mathrm{Ph}-\right)$, 9.40 (s, -NH-).

IR, $v\left(\mathrm{KBr}, \mathrm{cm}^{-1}\right)$ : $3319(\mathrm{~N}-\mathrm{H}), 3033,2957,2899(\mathrm{C}-\mathrm{H}), 1701$ $(\mathrm{C}=\mathrm{O}), 1597,1526,1414,1310,1225$ (C-O-C), 1065, 1016, 914, 814, 770 .

\section{Preparations of Segmented Polyurethane (SPU-2)}

In the above polymerization reaction for SPU-1, HO-PDMS $(2.66 \mathrm{~g}, 2.66 \mathrm{mmol})$ was used instead of HO-PTMG, and the similar reactions and reprecipitation were carried out to afford SPU-2 as a white powder. Yield: $5.00 \mathrm{~g}$ (97.3\%).

${ }^{1} \mathrm{H}$ NMR, $\delta\left(400 \mathrm{MHz}, \mathrm{DMSO}-d_{6}, \mathrm{ppm}\right): 0.01\left(\mathrm{~s},-\mathrm{Si}\left(\mathrm{CH}_{3}\right)_{2}\right)$, $0.52\left(\mathrm{~m},-\mathrm{SiCH}_{2}-\right), 1.53\left(\mathrm{~m},-\mathrm{CH}_{2}-\right), 1.73\left(\mathrm{~m},-\mathrm{CH}_{2}-\right), 3.32(\mathrm{~m}$, $\left.-\mathrm{CH}_{2}-\right), 3.40$ (m, - $\left.\mathrm{CH}_{2}-\right), 3.81$ (s, $\left.-\mathrm{PhCH}_{2} \mathrm{Ph}-\right), 4.28$ (m, $-\mathrm{CH}_{2}{ }^{-}$), $4.38\left(\mathrm{~m},-\mathrm{CH}_{2}-\right), 7.11$ (d, $\left.J=7.30 \mathrm{~Hz},-\mathrm{Ph}-\right), 7.38$ (d, $J=$ $7.80 \mathrm{~Hz},-\mathrm{Ph}-), 9.55$ (s, -NH-).

IR, v $\left(\mathrm{KBr}, \mathrm{cm}^{-1}\right): 3315(\mathrm{~N}-\mathrm{H}), 2961,2860(\mathrm{C}-\mathrm{H}), 1708$ $(\mathrm{C}=\mathrm{O}), 1590,1541,1508,1261$ (Si-C), 1025 (Si-O-Si), 798, 740 .

\section{Characterizations}

${ }^{1} \mathrm{H}$ NMR spectra were conducted with a JEOL NM-TH5SK $400 \mathrm{MHz}$ FT NMR spectrometer, and the chemical shifts were estimated in ppm units with tetramethylsilane (TMS) as an internal standard. Infrared (IR) spectra were recorded with a Shimadzu FT/IR-8400 spectrometer. The molecular weights of polymers were estimated by Tosoh gel permeation chromatography (GPC) system equipped with a pump of CCPD, three columns of TSK gels Multipore HXL-M, a column oven of CO-8010 and RI detector of RI-8010 in DMF eluent at $40^{\circ} \mathrm{C}$. Average molecular weights were calibrated based on polystyrene standards. Differential scanning calorimetry (DSC) was carried out on a Seiko Instruments DSC-6200 under a nitrogen flow rate of $30 \mathrm{~mL} / \mathrm{min}$ and a heating rate of $10^{\circ} \mathrm{C} / \mathrm{min}$.

\section{Preparations of Polymer Films}

The obtained polymers were dissolved in dimethylformamide (DMF) at about $10 \mathrm{wt}$ \%. Then, the solution was cast on the poly(ethylene terephthalate) sheet, and the solvent was evaporated at $60^{\circ} \mathrm{C}$ over a period of $24 \mathrm{~h}$ to form polymer films. The obtained films were dried for $2 \mathrm{~h}$ at $80^{\circ} \mathrm{C}$ in vacuo

\section{Surface Characterizations of Polymers}

The polymer films were cut into circular pieces with a diameter of $14 \mathrm{~mm}$ and a thickness of $0.1-0.2 \mathrm{~mm}$. Contact angles of water on the surfaces of the polymer films were measured using an Erma contact-angle microscope at room temperature. On the other hand, X-ray photoelectron spectroscopy (XPS) was conducted on the surface of polymer films by using ULVAC-PHI Quantum 2000 XPS apparatus. The take-off angle of the photoelectron was 45 degree.

\section{Evaluation of Blood Compatibility}

Whole blood was collected from healthy donors. In a polyethylene disposable syringe containing $3 \mathrm{~mL}$ of a $3.8 \mathrm{wt}$. \% aqueous sodium citrate solution, $30 \mathrm{~mL}$ of fresh blood was collected. The citrated whole blood was immediately centrifuged for $15 \mathrm{~min}$ at $1200 \mathrm{rpm}$ to obtain citrated platelet-rich plasma (PRP).

The circular pieces of polymer films were contacted with phosphate-buffered solution ( $\mathrm{PBS}, \mathrm{pH}=7.4$ ) at r.t. for overnight to equilibrate the surface, then the human whole blood or PRP was poured onto the films and incubated at $37^{\circ} \mathrm{C}$ for $60 \mathrm{~min}$. After the incubation, the whole blood and PRP were removed with an aspirator, and the films were rinsed three times with PBS, and then $0.7 \mathrm{~mL}$ of $2.5 \mathrm{vol} . \%$ glutaraldehyde in PBS was poured onto each film, and the materials were maintained at room temperature for $2 \mathrm{~h}$ in order to fix the blood components on the plates. After the fixation, it had been rinsed five times with distilled water, and then the plate was freezedried. The surfaces of the polymer films were observed with a scanning electron microscope (SEM) by using JEOL JSM-5200 after a gold-sputtering treatment.

\section{Measurement of the Amount of Platelets Adsorbed on the Polymer Surface}

After incubating the polymer films in the above procedure, PRP was removed and the films were washed 3 times with PBS and transferred into $0.5 \mathrm{wt}$. \% aqueous solution of polyethylene glycol mono- $p$-isooctylphenyl ether (Triton X100) to elute the adsorbed platelets. The concentration of platelets in the Triton X100 solution was counted by a lactate dehydrogenase (LHD) assay using an LDH-Cytotoxic Test Kit (Wako Chemicals, Osaka, Japan). The concentration of platelets in PRP was determined with a Coulter counter (MULTISIZER II, Beckman Coulter, CA) and the number of platelets that adhered on the polymer films was estimated based on the absorbance of the PRP-diluted system. 
Table I. Results of polymerizations

\begin{tabular}{|c|c|c|c|c|c|c|}
\hline \multirow{2}{*}{ Code } & \multirow{2}{*}{$\begin{array}{l}\text { Molar ratio of monomers } \\
\text { MDI:BD:HO-X-OH:DAPC }\end{array}$} & \multirow{2}{*}{$\begin{array}{l}\text { Yield } \\
(\%)\end{array}$} & \multicolumn{2}{|c|}{ PC content ${ }^{\mathrm{a})}$} & \multirow{2}{*}{$M_{\mathrm{n}}{ }^{\mathrm{b})} \times 10^{-3}$} & \multirow{2}{*}{$M_{\mathrm{w}} / M_{\mathrm{n}}^{\mathrm{b}}$} \\
\hline & & & $(\mathrm{mol} \%)$ & (wt. \%) & & \\
\hline SPU-1 & $6: 4: 2: 0$ & 96.3 & 0 & 0 & 104 & 2.11 \\
\hline SPUU-1a & $6: 3: 2: 1$ & 91.3 & 12.7 & 6.37 & 88.9 & 1.79 \\
\hline SPUU-1b & $6: 2: 2: 2$ & 85.7 & 27.6 & 12.5 & 77.4 & 1.56 \\
\hline SPUU-1C & $6: 1: 2: 3$ & 83.5 & 41.5 & 16.5 & 38.7 & 1.59 \\
\hline SPU-2 & $6: 4: 2: 0$ & 97.3 & 0 & 0 & 53.1 & 1.91 \\
\hline SPUU-2a & $6: 3: 2: 1$ & 92.7 & 12.5 & 6.23 & 44.4 & 2.23 \\
\hline SPUU-2b & $6: 2: 2: 2$ & 87.1 & 26.4 & 11.8 & 44.0 & 2.32 \\
\hline
\end{tabular}

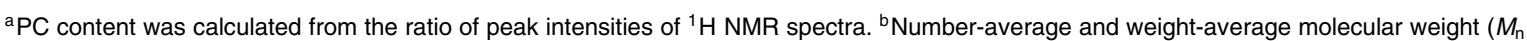
and $M_{\mathrm{w}}$ ) were determined by GPC based on polystyrene standards.

\section{Measurements of Mechanical Strength}

The polymer films were cut into rectangular strips with a length of $70 \mathrm{~mm}$, a width of $15 \mathrm{~mm}$ and a thickness of $0.1-$ $0.2 \mathrm{~mm}$. Stress-strain curves were obtained on a JT Torsi LSC$01 / 30$, where the gauge length was $50 \mathrm{~mm}$ and the crosshead speed was $12 \mathrm{~mm} / \mathrm{min}$.

\section{Measurements of Gas Permeability Coefficients}

Sample films were cut into circular pieces with a diameter of $36 \mathrm{~mm}$ and a thickness of $0.1-0.2 \mathrm{~mm}$. Gas permeabilities of the membranes were measured using the ordinary vacuum method at $30^{\circ} \mathrm{C}$ with the apparatus, Tsukuba-Rikaseiki K-315N-01, where the permeation area was $7.07 \mathrm{~cm}^{2}$. The gas permeability coefficients $\left(P, \mathrm{~cm}^{3}(\mathrm{STP}) \cdot \mathrm{cm} \cdot \mathrm{cm}^{-2} \cdot \mathrm{s}^{-1} \cdot \mathrm{cmHg}^{-1}\right)$ were calculated from the slope of the time-pressure curve, $d p / d t$, in the steady state.

\section{RESULTS AND DISCUSSION}

\section{Synthesis of Segmented Poly(urethane-urea) Containing PC Unit}

At first, two kinds of segmented oligourethanes were prepared by polyaddition of $4,4^{\prime}$-diphenylmethane diisocyanate (MDI) with 1,4-butanediol (BD) in NMP, followed by the addition of hydroxyl-terminated poly(tetramethylene glycol) (HO-PTMG) or hydroxyethoxypropyl-terminated polydimethylsiloxane (HO-PDMS) as the soft segment. In the polymerization vessels, 2-(3,5-diaminophenylcarbonyloxy)ethyl phosphorylcholine (DAPC) was finally added to couple the oligourethanes to obtain segmented poly(urethane-urea)s containing PC unit (SPUU-1a,b,c and SPUU-2a,b), as shown in Scheme 1. The similar segmented polyurethanes without PC unit (SPU-1 and SPU-2) were prepared from MDI and BD with HO-PTMG or HO-PDMS as reference samples. These polymerization reactions proceeded smoothly by using dibutyltin dilaurate (DBTDL) as a catalyst, whereas the low molecular weight polymers were obtained in very low yields without using DBTDL. In addition, the catalyst could be efficiently removed by the reprecipitaion of polymer solutions into methanol/diethyl ether mixed solvents.

Table I summarizes the results of polymerizations. Several poly(urethane-urea)s with different contents of PC unit were prepared by changing the amount of DAPC in the polyaddition.
In the case of SPUU-2 series, the higher PC content more than $26 \mathrm{~mol} \%$ could not be achieved, because the polymer was not precipitated when DAPC was used higher than the equimolar amount of BD or HO-PDMS. The chemical structures of these polymers were confirmed by their ${ }^{1} \mathrm{H}$ NMR and IR spectra, as described in the experimental section. The compositions of PC unit in SPUU-1 and SPUU-2 series were determined from the ratio of the peak intensities of the ammonium proton (3.10$3.15 \mathrm{ppm})$ of PC unit and methylene proton $(3.78-3.80 \mathrm{ppm})$ of $p, p^{\prime}$-diphenylmethane unit, where the $p, p^{\prime}$-diphenylmethane unit was exist in every monomer components. The observed PC content in mol\% was a little lower than the molar ratio of DAPC against all of the diol monomers, and the yields were decreased as the PC content increased. Probably, the highly hygroscopic property of DAPC would disturb the polyaddition using a moisture-sensitive MDI. In IR spectra, the absorption peaks of the urethane and urea groups were observed at $3315 \mathrm{~cm}^{-1}$ and $1710 \mathrm{~cm}^{-1}$, and the PC group was identified from the peak at $1240 \mathrm{~cm}^{-1}$. The number-average molecular weights $\left(M_{\mathrm{n}}\right)$ of the obtained polymers were over $10^{4}$, and tough films were prepared from these SPU and SPUU by a solvent casting method.

The SPUU-1 series containing PTMG segment exhibited a good solubility in aprotic polar solvents such as NMP, DMF and DMSO at room temperature, whereas it was insoluble in methanol, ethanol, acetone, tetrahydrofuran (THF) and water. By the way, the SPUU-2 series containing PDMS segment was soluble in NMP, DMF, DMSO and THF, but insoluble in methanol, ethanol, acetone and water. Therefore, the solubility of SPUU-1 series was slightly different from that of SPUU-2 series due to their difference of soft segment. Such a solubility in the specific solvents is advantageous in the processing for medical devices, and the insolubility in other solvents enables the material durable to these solvents. From the results of DSC measurements, SPUU-1 and SPUU-2 series were glassy polymers, the glass transition $\left(T_{\mathrm{g}}\right)$ of which was not observed in the range of $-50{ }^{\circ} \mathrm{C}-250^{\circ} \mathrm{C}$, although SPU-1 showed the melting point $\left(T_{\mathrm{m}}\right)$ at $215^{\circ} \mathrm{C}$. Such a thermal stability of these polymers would be sufficient for the applications to biomaterials and medical devices, especially in the sterilization process.

Therefore, as compared with MPC polymer, it was found that the physical characteristics of SPUU-1 and SPUU-2 series 


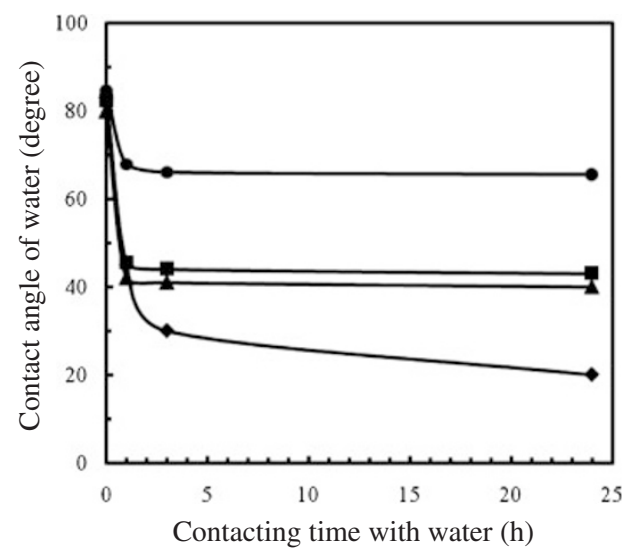

(A)

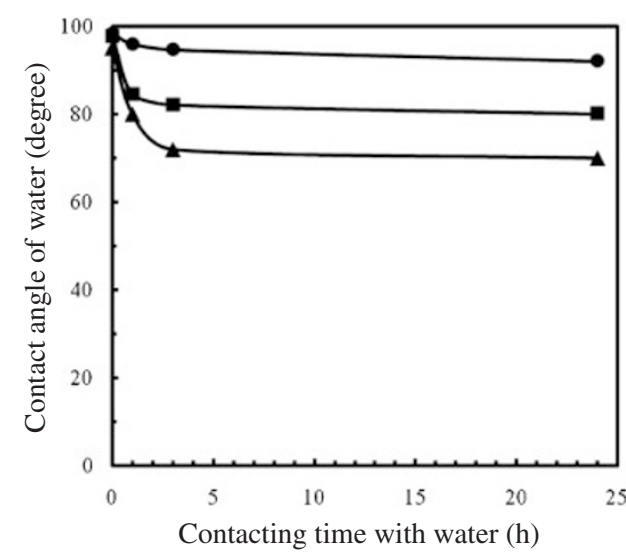

(B)

Figure 1. The time course of contact angle of water on the polymer films after treatment with water. (A) @: SPU-1, $\square:$ SPUU-1a, $\mathbf{\Delta}:$ SPUU-1b, $\bullet:$ SPUU-1c. (B) : SPU-2, ㅁ: SPUU-2a, $\mathbf{A}:$ SPUU-2b.
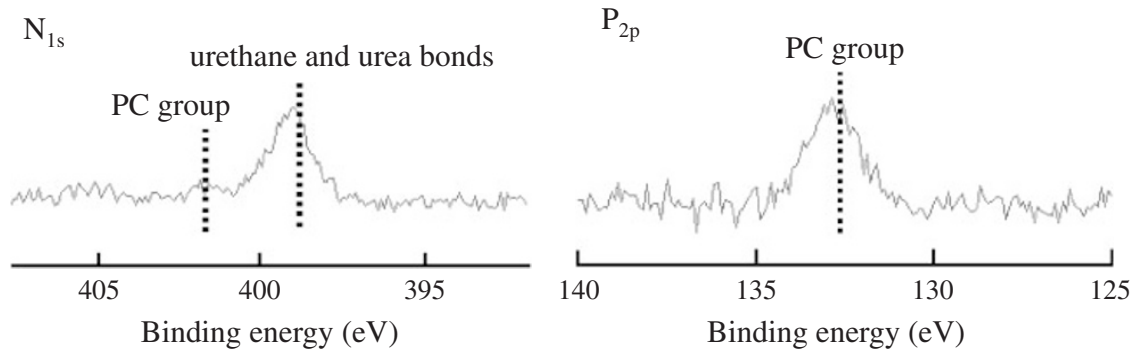

Figure 2. XPS spectra of SPUU-1c film.

exhibited the durability to common organic solvents such as alcohols and the higher thermal stability, whereas the MPC polymer were easily soluble in common organic solvents and softened at $T_{\mathrm{g}}$ of below $100^{\circ} \mathrm{C}$.

\section{Surface Property}

The surface analysis of the polymer films was carried out, in order to clarify the effect of PC group on the surface property of SPUU-1 and SPUU-2 series. Figure 1 shows the time-course of contact angle of water on the surface of polymer films after the films were immersed in water. In the cases of SPU-1 and SPU2 without PC unit, the contact angle showed almost no change after immersed in water during 1-24 h, where the film surfaces became slightly hydrophilic by the contact with water to give a certain decrease of contact angle at the first stage. The value of SPU-2 was higher than that of SPU-1, which would be due to the hydrophobic PDMS segment of SPU-2. On the other hand, the contact angles of the SPUU-1 and SPUU-2 films were significantly decreased after the films were immersed in water, where SPUU-1c film showed the great decrease of the contact angle with contacting time of water. Therefore, the surface of the polymer membrane became hydrophilic by the introduction of PC unit and by contacting the surface with water. This result indicated that SPUU-1 and SPUU-2 film surfaces were largely swelled by water and the PC group of polymers was oriented to the water-side. The similar tendency was observed for polyamides containing PC unit in the side chain. ${ }^{27}$
Furthermore, the surface chemical structure of SPUU-1c film was analyzed by X-ray photoelectron spectroscopy (XPS), as shown in Figure 2. The XPS signals observed at 133, 398 and $402 \mathrm{eV}$ in $\mathrm{P}_{2 \mathrm{p}}$ and $\mathrm{N}_{1 \mathrm{~s}}$ regions were attributed to phosphorus of the phosphate group, the nitrogen atoms in the urethane or urea bond (-NH-) and the ammonium group $\left(-\mathrm{N}^{+}\left(\mathrm{CH}_{3}\right)_{3}\right)$, respectively. Then, PC group was clearly observed on the SPUU-1c film surface. However, these peaks were not so clear on the surfaces of SPUU-1a, SPUU-1b, SPUU-2a and SPUU-2b films. Therefore, in this poly(urethane-urea) system, PC content should be over ca. 15 wt. \% to make the PC group clearly appear on the surface of polymer film.

\section{Biocompatibility}

The blood compatibility of the polymer films was evaluated by contacting the films with a human blood, to reveal the effect of PC unit on the biocompatibility of polymers. Figure 3 shows the number of platelets adhered on the polymer films and the SEM pictures of SPU-1 and SPUU-1c films after contact with PRP for $1 \mathrm{~h}$. The numerous adherent human platelets on the SPU-1 film surface were observed as large aggregates. On the contrary, the platelets were significantly suppressed on the SPUU-1b, SPUU-1c and SPUU-2b film surfaces as shown in Figure 3. The numbers of adhered platelets on SPUU-1b, SPUU-1c and SPUU-2b films were 3.0, 1.5 and $3.3\left(\times 10^{6}\right.$ cells $\left./ \mathrm{cm}^{2}\right)$, whereas those on SPU-1 and SPU-2 films were 8.4 


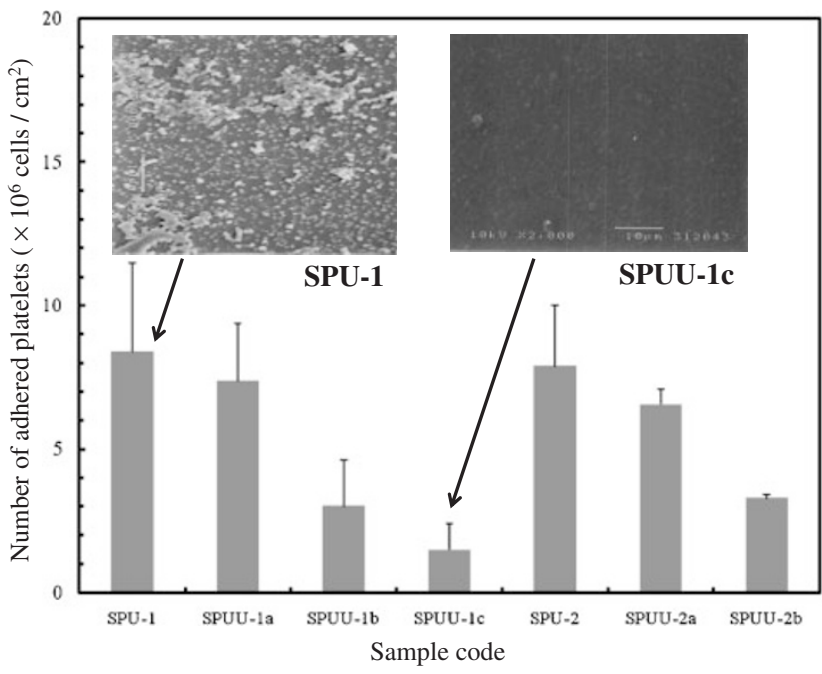

Figure 3. Number of adherent platelets and SEM pictures $(x 2,000)$ on the polymer surfaces after contact with human platelet rich plasma (PRP) for $60 \mathrm{~min}$. Each bar represents mean \pm S.E. for 4 experiments.

and $7.9\left(\times 10^{6}\right.$ cells $\left./ \mathrm{cm}^{2}\right)$, respectively. These results clearly indicated that SPUU-1b, SPUU-1c and SPUU-2b exhibited the excellent blood compatibility and that PC unit in the poly(urethane-urea) was an appropriate component to develop the blood compatibility, where $c a$. $10 \mathrm{wt}$. \% of PC content was enough to reduce the adhesion of platelets. Furthermore, the composition of the PC unit was a dominant factor in the reduction of the blood cell and platelet adhesion, which was revealed from the result that the number of adhered platelets was much decreased on SPUU-1c film rather than SPUU-1b and SPUU-2b films. Thus, the PC content of $16.5 \mathrm{wt} \%$ in SPUU-1c was necessary to sufficiently reduce the adhered platelets on the polymer surfaces, which would be an enough content of the PC unit located at the surface of the polymer film.

However, the reduction of the adhered platelets on the MPC polymer (PMB) film was more effective than SPUU-1c, where the number of adhered platelets on PMB surface was less than $1 \times 10^{6}$ cells $/ \mathrm{cm}^{2}$ in the same condition. Probably, the density of PC group on the surface of SPUU-1c would be lower than that of MPC polymer, because of the limitation of PC content in this polyaddition system.

\section{Mechanical Property}

The mechanical properties of SPU and SPUU films were evaluated in order to reveal the effect of introduction of PC unit on the mechanical property of polyurethane backbone. Figure 4 shows the stress-strain behaviors of all the polymer films prepared in this study, and the Young's modulus, the tensile strength and the elongation to break were summarized in Table II. As seen in Figure 4, the similar tendency was observed in all of the polymer films except SPUU-1c, although the tensile strength of SPU-2 and SPUU-2 series was higher than that of SPU-1 and SPUU-1 series. Consequently, there
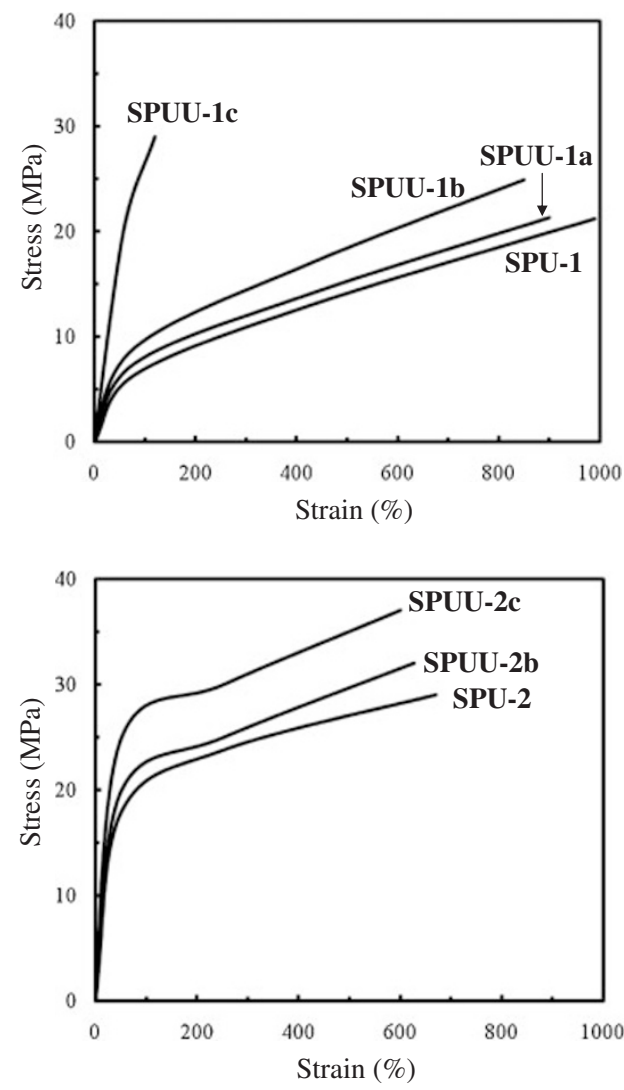

Figure 4. Stress-Strain behaviors of SPU and SPUU films. Gauge length: $50 \mathrm{~mm}$, Width: $15 \mathrm{~mm}$, Thickness: $0.1-0.2 \mathrm{~mm}$, Elongation rate: $12 \mathrm{~mm} / \mathrm{min}$.

Table II. Mechanical properties of SPU and SPUU films

\begin{tabular}{lccc}
\hline Code & $\begin{array}{c}\text { Young's modulus } \\
(\mathrm{MPa})\end{array}$ & $\begin{array}{c}\text { Tensile strength } \\
(\mathrm{MPa})\end{array}$ & $\begin{array}{c}\text { Elongation to break } \\
(\%)\end{array}$ \\
\hline SPU-1 & 106 & 21.2 & 1010 \\
SPUU-1a & 119 & 21.3 & 912 \\
SPUU-1b & 132 & 24.9 & 850 \\
SPUU-1c & 345 & 31.6 & 120 \\
SPU-2 & 208 & 28.9 & 670 \\
SPUU-2a & 220 & 31.7 & 627 \\
SPUU-2b & 281 & 37.0 & 600 \\
\hline PMBH & 15 & 3.6 & 390 \\
\hline
\end{tabular}

*PMBH: poly(MPC-co-2-ethylhexyl methacrylate) (MPC content: 26 $\mathrm{mol} \%)$, the values of which were described in the literature. ${ }^{20}$

was almost no change in such elastic stress-strain behaviors between SPU and SPUU series, the PC content of which was less than 12 wt. \%. However, SPUU-1c containing 16.5 wt. \% of PC unit exhibited also the elastic property, although the elongation at break of SPUU-1c was lower than that of SPUU1a and SPUU-1b. Furthermore, the Young's modulus and the tensile strength increased with the increase of PC unit of SPUU-1 and SPUU-2 series, as listed in Table II. The increase of the mechanical strength would be due to the increase of urea bond, which would enhance the molecular interaction in the hard segments rather than urethane bond. In addition, as shown 
Table III. Gas permeability and solubility and diffusion parameters of SPU-2 and SPUU-2b films

\begin{tabular}{|c|c|c|c|c|c|c|}
\hline \multirow{2}{*}{$\begin{array}{c}\text { Sample code } \\
\text { and parameters }\end{array}$} & \multicolumn{6}{|c|}{ Gas permeability coefficient $(P)$ and $S, D$ parameters ${ }^{\text {a) }}$} \\
\hline & $\mathrm{H}_{2}$ & $\mathrm{CO}_{2}$ & $\mathrm{O}_{2}$ & $\mathrm{~N}_{2}$ & $\mathrm{CH}_{4}$ & $\mathrm{C}_{2} \mathrm{H}_{6}$ \\
\hline \multicolumn{7}{|l|}{ SPU-2 } \\
\hline$P\left(\right.$ Barrer $\left.^{\mathrm{b})}\right)$ & 105 & 428 & 77.3 & 32.8 & 103 & 251 \\
\hline$S\left(10^{-5} \mathrm{~cm}^{3}(\mathrm{STP}) / \mathrm{cm}^{3} \cdot \mathrm{cmHg}\right)$ & 24.1 & 769 & 112 & 26.5 & 203 & 1150 \\
\hline$D\left(10^{-7} \mathrm{~cm}^{2} / \mathrm{s}\right)$ & 437 & 55.6 & 69.1 & 123 & 50.9 & 21.8 \\
\hline \multicolumn{7}{|l|}{ SPUU-2b } \\
\hline$P\left(\right.$ Barrer $\left.^{\mathrm{b})}\right)$ & 124 & 505 & 91.5 & 40.0 & 124 & 306 \\
\hline$S\left(10^{-5} \mathrm{~cm}^{3}(\mathrm{STP}) / \mathrm{cm}^{3} \cdot \mathrm{cmHg}\right)$ & 95.5 & 1150 & 125 & 56.2 & 267 & 1630 \\
\hline$D\left(10^{-7} \mathrm{~cm}^{2} / \mathrm{s}\right)$ & 130 & 44.0 & 73.2 & 71.2 & 46.5 & 18.7 \\
\hline
\end{tabular}

${ }^{\text {a }} \mathrm{S}$ : Solubility parameter, $D$ : Diffusion parameter. ${ }^{\mathrm{b}} 1$ Barrer $=10^{-10} \mathrm{~cm}^{3}(\mathrm{STP}) \cdot \mathrm{cm} / \mathrm{cm}^{2} \cdot \mathrm{s} \cdot \mathrm{cmHg}$

in Table II, the mechanical properties of these poly(urethaneurea)s and MPC polymer (PMEH) films were quite different, where Young's moduli of SPUU-1c and PMEH were 345 and $15 \mathrm{MPa}$, respectively. These physical properties of these polymers obviously depended on the elastic segmented polyurethane backbone.

\section{Gas Permeability}

As described above, it was found that PC group was effective to change the polymer film surface when the PC content was above $10 \mathrm{wt}$ \%, and that the tough films could be prepared from these polymers. Then, the gas permeabilities of SPU-2 and SPUU-2b were evaluated to reveal the effect of PC unit on the gas permeability of polymer film, which consisted of the high permeable polysiloxane segment. Gas permeability coefficients of SPU-2 and SPUU-2b films for nitrogen, oxygen, hydrogen, carbon dioxide, methane and ethane were evaluated, as listed in Table III. It was noticed from this table that the gas permeability of the two films were relatively high according to the PDMS backbone component. Interestingly, the gas permeability coefficients of SPUU-2b film were slightly higher than those of SPU-2. Therefore, the solubility and diffusion parameters were also calculated from the time lag in the slope of time-pressure curve, $d p / d t$, to predict the mechanism. As a result, the solubility parameters of all of the gases on the SPUU-2b film surface were higher as compared with SPU-2 film, as shown in Table III. It was speculated that the surface property, which was derived from the introduction of PC group, increased the gas permeability of polymers due to the increase of gas solubility on the polymer surface. Iwasaki et al. have been reported the oxygen permeability in water through the skin films consisted of MPC polymer, poly(MPC-cododecyl methacrylate) (PMD), adhered on a polyethylene porous membrane, where the oxygen permeability coefficients were increased as the increase of MPC content. ${ }^{28}$ The tendency of gas permeability of SPUU-2b film corresponds to those results of composite films containing MPC polymer, although the permeabilities have been investigated in different conditions and the mechanism of such improved gas permeability by PC unit has been still unclear.

If the high gas permeable and biocompatible membrane is developed, several applications will be expected, such as the artificial lung or the separation membranes without adhesion of bio-components. Thus, we are planning to develop the higher permeable membrane materials with a biocompatibility based on PC group.

\section{CONCLUSION}

An aromatic diamine compound containing PC group, DAPC, was used as a coupling reagent in the synthesis of segmented polyurethane to yield poly(urethane-urea)s with different PC contents. The introduction of such a polar group of phospholipid was effective to improve the blood compatibility even in the segmented polyurethane system, which would be due to the surface property covered with PC moiety. Furthermore, the elastic mechanical properties of segment polyurethane were maintained when the PC unit was introduced up to 17 wt. \%. On the other hand, the gas permeability of the poly(urethane-urea) film, which consisted of the high permeable siloxane soft segment, slightly increased as compared with polyurethane film due to the effect of surface rearrangement by PC moiety. Consequently, it is expected that such poly(urethane-urea)s containing PC group will be useful polymeric biomaterials to develop a new generation of biomedical devices, because of the different solubility, the higher mechanical strength and the similar biocompatibility as compared to the MPC polymer.

However, it is considered that the PC content should be increased to improve the biocompatibility, which is not enough for the practical use. To improve the PC content in this system, the molecular design of the higher reactive diamine monomer containing PC unit must be developed, which is now in progress.

Acknowledgment. The authors express their sincere gratitude to Associate Professor Takashi Asaka, Department of Applied Chemistry, Tokai University, for his help to conduct the stress-strain measurement. This work was partially supported by a Grant-in-Aid for Scientific Research from the Ministry of Education, Culture, Sports, Science and Technology, Japan (No. 15550110).

Received: July 10, 2008 Accepted: August 27, 2008 Published: October 8, 2008 


\section{REFERENCES}

1. M. D. Lelah and S. L. Cooper, "Polyurethanes in Medicine," Boca Raton, CRC Press, 1986.

2. C. D. Eisenbach, K. Fischer, H. Hayen, H. Nefzger, A. Ribbe, and E. Stadler, Polym. Mater. Encycl., 9, 6957 (1996).

3. Q. Zhao, N. Topham, J. M. Anderson, A. Hiltner, G. London, and C. R. Payet, J. Biomed. Mater. Res., 25, 177 (1991).

4. Y. Wu, Q. Zhao, J. M. Anderson, A. Hiltner, G. M. London, and C. R. Payet, J. Biomed. Mater. Res., 25, 725 (1991).

5. Q. H. Zhao, A. K. McNally, K. R. Rubin, M. Renier, and Y. V. Wu, J. Biomed. Mater. Res., 27, 379 (1993).

6. K. Stokes, R. McVenes, and J. M. Anderson, J. Biomater. Appl., 9, 321 (1995).

7. I. K. Kang, O. H. Kwon, M. K. Kim, Y. M. Lee, and Y. K. Sung, Biomaterials, 18, 1099 (1997).

8. R. G. Flemming, R. A. Proctor, and S. L. Cooper, J. Biomater. Sci., Polym. Ed., 10, 679 (1999).

9. A. B. Mathur, T. O. Collier, W. J. Kao, M. Wiggins, M. A. Schubert, A. Hiltner, and J. M. Anderson, J. Biomed. Mater. Res., 36, 246 (1997).

10. H. W. Roh, M. J. Song, D. K. Han, D. S. Lee, J. H. Ahn, and S. C. Kim, J. Biomater. Sci. Polym. Ed., 10, 123 (1999).

11. J. H. Lee, Y. M. Ju, and D. M. Kim, Biomaterials, 21, 683 (2000).

12. K. Ishihara, T. Ueda, and N. Nakabayashi, Polym. J., 22, 355 (1990).

13. T. Ueda, H. Oshida, K. Kurita, K. Ishihara, and N. Nakabayashi, Polym. J., 24, 1259 (1992).

14. K. Sugiyama, K. Ohga, H. Aoki, and N. Amaya, Macromol. Chem. Phys., 196, 1907 (1995).
15. T. Oishi, T. Fukuda, H. Uchiyama, F. Kondou, H. Ohe, and H. Tsutsumi, Polymer, 38, 3109 (1997).

16. K. Ishihara, N. P. Ziats, B. P. Tierney, N. Nakabayashi, and J. M. Anderson, J. Biomed. Mater. Res., 25, 1397 (1991).

17. K. Ishihara, H. Inoue, K. Kurita, and N. Nakabayashi, J. Biomed. Mater. Res., 28, 1347 (1994).

18. K. Ishihara, T. Tsuji, T. Kurosaki, and N. Nakabayashi, J. Biomed. Mater. Res., 28, 225 (1994).

19. K. Ishihara and Y. Iwasaki, Polym. Adv. Technol., 11, 626 (2000).

20. T. Uchiyama, J. Watanabe, and K. Ishihara, J. Membr. Sci., 210, 423 (2002).

21. T. Moro, Y. Takatori, K. Ishihara, T. Konno, Y. Takigawa, T. Matsushita, U. Chang, K. Nakayama, and H. Kawaguchi, Nat. Mater., 3, 829 (2004).

22. N. Morimoto, A. Watanabe, Y. Iwasaki, K. Akiyoshi, and K. Ishihara, Biomaterials, 25, 5353 (2004).

23. K. Ishihara, H. Hanyuda, and N. Nakabayashi, Biomaterials, 16, 873 (1995).

24. K. Ishihara, S. Tanaka, N. Furukawa, K. Kurita, and N. Nakabayashi, J. Biomed. Mater. Res., 32, 391 (1996).

25. K. Ishihara, N. Shibata, S. Tanaka, Y. Iwasaki, T. Kurosaki, and N. Nakabayashi, J. Biomed. Mater. Res., 32, 401 (1996).

26. Y. Iwasaki, Y. Aiba, N. Morimoto, N. Nakabayashi, and K. Ishihara, J. Biomed. Mater. Res., 52, 701 (2000).

27. Y. Nagase, M. Oku, Y. Iwasaki, and K. Ishihara, Polym. J., 39, 712 (2007).

28. Y. Iwasaki, S. Uchiyama, K. Kurita, N. Morimoto, and N. Nakabayashi, Biomaterials, 23, 3421 (2002). 